\title{
Endoscopic laser treatment for rectosigmoid villous adenoma: Factors affecting the results
}

\author{
JM BRUNeTAUd, MD, V MAUNOURY, MD, D COCHELARD, MD, B BONIFACE, MD, \\ A CORTOT, MD, JC PARIS, MD
}

JM BRUNETAUD, V MAUNOURY, D COCHELARD, B BONIFACE, A CORTOT, JC PARIS. Endoscopic laser treatment for rectosigmoid villous adenoma: Factors affecting the results. Can J Gastroenterol 1992;6(5):301-307. Endoscopic laser treatment is now commonly used for palliation of advanced digestive cancers in nonsurgical candidates. It has also been used for treatment of benign rectosigmoid villous adenoma. The present work reports the long term results in 387 patients with benign rectosigmoid villous adenomas revealed by biopsy. Patients included $39 \%$ who had contraindications to surgery, $19 \%$ who had a tumour recurrence after a nonlaser treatment, $41 \%$ for whom surgical resection appeared to be too drastic for a tumour found benign on biopsy, and $1 \%$ who refused surgery. Two types of wavelength were used: the $1.06 \mu \mathrm{m}$ infrared light from the Nd:YAG laser and the green light from the argon laser or the Nd:YAG frequency doubled laser. In some patients, both wavelengths were used. Treatment was completed in 343 patients. Total tumour destruction was achieved in $92.8 \%$ of patients, a carcinoma was detected in $6.4 \%$ on biopsy specimens obtained during laser treatment and benign villous tissue persisted in $0.8 \%$. During the average 30 -month follow-up period of the patients with total tumour destruction, $16 \%$ had a recurrence. Treatment was well-tolerated with a complication rate of $2.3 \%$ (one patient with a perforation, one with hemorrhage and seven with stenosis requiring dilation). Circumferential extension of the tumour base was the only factor affecting the duration of treatment, the rate of cancers detected during treatment and the rate of complications. Recurrence rate after initial treatment was higher in patients treated for a recurrence after a previous nonlaser treatment than in patients treated only by laser $(P<0.01)$. It was also higher when the initial histology showed low grade dysplasia as opposed to high grade dysplasia $(\mathrm{P}<0.01)$ and when the tumour was located in the lower or middle rectum rather than in the upper rectum or sigmoid $(P<0.01)$. Direct cost of laser treatments was estimated to be 28 to $40 \%$ of the surgery charges for lesions of identical size in the authors' hospital and 31 to $69 \%$ at UCLA Center for the Health Sciences. Because treatment is long and difficult and cancer rate is high, endoscopic laser therapy should be limited in patients with a circumferential

Centre Multidisciplinaire de traitement par Laser, INSERM Unit 279, Clinique des Maladies de l'Appareil Digestif., Hopital Regional 59037, Lille Cedex et Laboratoire de Biomathematiques, Faculté de Pharmacie, Lille, France

Correspondence and reprints: Dr JM Brunetaud, Centre Multidisciplinaire de traitement par laser, Hopital Huriez, 59037, Lille Cedex, France
E NDOSCOPIC LASER TREATMENT IS commonly used for palliation of advanced digestive cancers in nonsurgical candidates $(1,2)$. It has also been used for treatment of biopsy benign rectosigmoid villous adenoma. A preliminary study involving 56 patients was pub. lished in 1985 (3). This present work reports the long term results of a much larger series with a retrospective study of factors affecting the results.

\section{PATIENTS AND METHODS}

Patients: Four hundred and twenty-five patients were referred by gastroenterologists or surgeons to the Lille Laser Center from December 1979 to July 1991 for benign sessile rectosigmoid villous adenoma. The indication for laser treatment was reconsidered during a pretreatment evaluation as a function of the general condition of the patient, the extension of the tumour base and the results of new biopsies or diathermic snare resections done at the laser center. Surgical treatment was considered to be more appropriate in 24 patients and the tumour was found to be malignant on the initial biopsies performed at the laser center in 14 other patients.

Three hundred and eighty-seven patients were treated for rectosigmoid villous adenoma. The average age was 71 years (range 32 to 96). Indications for laser treatment were: nonsurgical 
villous adenoma to nonsurgical candidates. Risk of complications following surgery has to be balanced against risk of undetected carcinoma and the indication for endoscopic laser treatment should be discussed case by case.

\section{Key Words: Endoscopic treatment, Nd:YAG laser, Villous adenoma}

\section{Facteurs en jeu dans l'issue du traitement endoscopique au laser de la tumeur villeuse rectosigmoïdienne}

RÉSUMÉ: Le traitement endoscopique au laser est maintenant fréquemment utilisé à titre palliatif dans les cas de cancers avancés des voies digestives chez les patients non opérables. Il a également été utilisé dans le traitement des tumeurs villeuses rectosigmoïdiennes bénignes. La présente recherche fait état de résultats à long terme obtenus auprès de 387 patients atteints de tumeurs villeuses rectosigmoïdiennes révélées par la biopsie. Les patients étaient répartis comme suit: chez $39 \%$ d'entre eux, la chirurgie était contre-indiquée, $19 \%$ presentaient une récurrence de tumeur après un traitement autre qu'au laser, chez $41 \%$, la résection chirurgicale semblait trop draconienne, compte tenu que la tumeur était bénigne à la biopsie, et $1 \%$ a refusé la chirurgie. Deux types de longueurs d'ondes ont été utilisés: la lumière infra-rouge 1,06 pn du laser Nd:YAG et la lumière verte du laser à l'argon ou le laser à double fréquence $\mathrm{Nd}$ :YAG. Chez certains patients, les deux longueurs d'ondes ont été utilisées. Le traitement a été complété chez 343 patients. La tumeur a été totalement détruite chez 92,8\% d'entre eux; un cancer a été détecté chez $6,4 \%$ des patients, à la biopsie prélevée durant le traitement au laser et la présence de tissu villeux bénin a persisté chez $0,8 \%$ d'entre eux. Au cours de la période de suivi d'une durée moyenne de 30 mois, chez les patients dont la tumeur avait été totalement détruite, $16 \%$ ont connu une récurrence. Le traitement fut bien toléré, avec un taux de complication de $2,3 \%$ (un patient a subi une perforation, un autre, une hémorragie et sept, une sténose nécessitant la dilatation). L'extension circonférentielle de la base de la tumeur a été le seul facteur à influer sur la durée de l'intervention, le taux de détection de tumeurs cancéreuses et le taux de complication. La taux de récurrence après le traitement initial fut plus élevé chez les patients traités pour une tumeur récurrente traitée autrement qu'au laser que chez les patients traités uniquement par laser $(\mathrm{P}<0,01)$. Il le fut également lorsque l'histologie initials révélait une degré faible de dysplasie, par opposition à un degré élevé de dysplasie et lorsque la tumeur se situait la partie inférieure ou médiane du rectum plutôt qu'au niveau supérieur ou sigmoïdien. Le coût direct des traitements au laser représente environ de 28 à $40 \%$ des frais de chirurgie pour des lésions de taille identique au centre hospitalier au pratiquent les auteurs et de 31 à $9 \%$ de ceux encourus par le Centre des sciences de la santé de l'Université de Californie à Los Angeles. Le traitement endoscopique au laser doit être limité aux patients non opérables qui présentent une tumeur villeuse circonférentielle, parce que l'intervention est longue et difficile et que le taux de cancer est élevé. Le risque de complications post-opératoires doit être mesuré par rapport au risque de cancer non décelé chez les autres patients et l'indication du traitement endoscopique au laser doit être évaluée cas par cas.

patients (152 patients, 39\% of total); patients for whom rectosigmoid resection appeared to be too drastic for a tumour found benign on biopsy ( 158 patients, $41 \%$ of total); recurrent tumour after a previous nonlaser treatment ( 74 patients, $19 \%$ of total); and patient's refusal of surgery (three patients, $1 \%$ of total). The circumferential extension of the tumour base was graded from 1 to 3 . Cl indicates less than one-third circumference, $\mathrm{C} 2$ indicates more than one-third but less than two-thirds circumference and $\mathrm{C} 3$ indicates more than two-thirds circumference. Location and circumferential extension of the tumour base are shown in Figure 1. Material for histology was obtained during the pretreatment evaluation by diathermic resection of large particles in 25\% of the patients and by forceps biopsy in $75 \%$. A tumour was considered benign when the neoplastic tissue did not penetrate the muscularis mucosae. This occurred in all patients studied herein. Two grading systems were used to classify the dysplasia (4-5). Low grade dysplasia was observed in 309 patients $(80 \%)$ and high grade occurred in 78 patients (20\%). New biopsies were performed during the last part of the treatment and whenever there was a question of malignancy macroscopically.

Laser treatment modalities: Patients were treated on an outpatient basis, without anesthesia or premedication. Patients were prepared with a small enema at the laser center and no special diet was required before treatment. Exophytic villous adenomas were debulked with diathermic snare whenever possible before laser treatment (3). Patients were treated twice a week until complete destruction of the tumour and then followed twice a month until complete re-epithelialization.

The technique of using both argon and $\mathrm{Nd}$ :YAG lasers has been described elsewhere $(3,6)$. The argon laser was used for vaporization of superficial tumour (until a flat surface was obtained) at a power of $8 \mathrm{~W}$ and a spot size of $1 \mathrm{~mm}$ (irradiance: $1000 \mathrm{~W} / \mathrm{cm}^{2}$ ) with a continuous beam. Delayed necrosis is negligible after argon laser vaporization. The Nd:YAG laser was used for coagulation (blanching) of bulky tumour; and a three-day interval between treatments allowed the coagulated parts of the tumour to slough off. Reproducible effects without unexpected necrosis were obtained at $70 \mathrm{~W}, 2$ $\mathrm{mm}$ spot size (irradiance: $2000 \mathrm{~W} / \mathrm{cm}^{2}$ ) and 0.7 s exposure time.

Since March 1990, frequency doubled Nd:YAG laser, Multilase 2500 (Technomed International, Lyon, France), has been used at the centre. This laser gives either $100 \mathrm{~W}$ at 1.06 $\mu \mathrm{m}$ or $18 \mathrm{~W}$ at $0.532 \mu \mathrm{m}$. The yellowgreen $0.532 \mu \mathrm{m}$ wavelength was found to have almost the same effects of vaporization as the blue-green argon light. This laser has two advantages over the previous association of argon and Nd:YAG lasers. The higher optic power in the green shortens the treatment time and the switch from infra- 


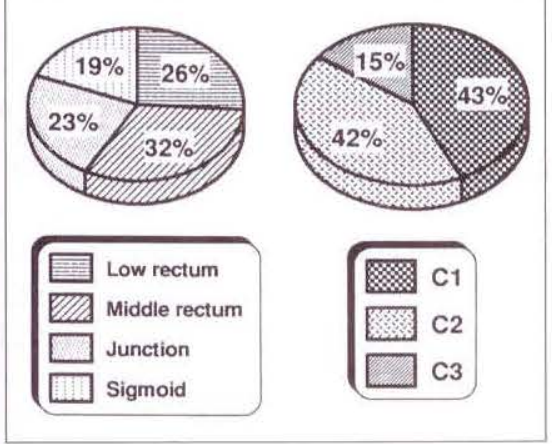

Figure 1) Location and circumferential extension of 387 villous adenomas. C1 indicates less than one-third circumference; C2 indicates between one-third and two-thirds circumference; C3 indicates more than two-thirds circumference

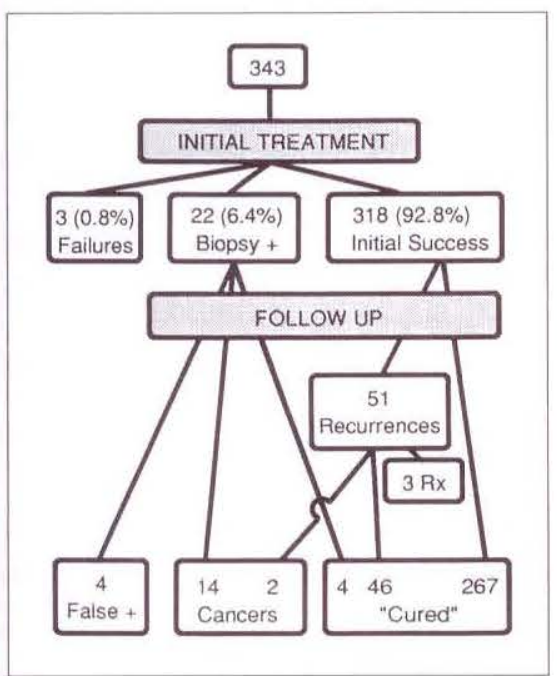

Figure 2) Results from laser treatment in 343 patients with a rectosigmoid villous adenoma. Rx Treatment of the recurrence not completed

red to green light is obtained by pushing a button, without removing the fibre from the endoscope.

Sixty-seven per cent of patients were treated with $1.06 \mu \mathrm{m} \mathrm{Nd:YAG}$ laser, 18\% with green light (argon or $0.532 \mu \mathrm{m} \mathrm{Nd:YAG)}$ and $15 \%$ with infrared and green light.

Evaluation: Initial treatment was considered successful when total destruction of the villous adenoma was obtained with re-epithelialization by normal mucosa. The patients were then re-endoscoped to detect a possible recurrence every three months during the first two years of follow-up and then every year. The frequency of recurren-

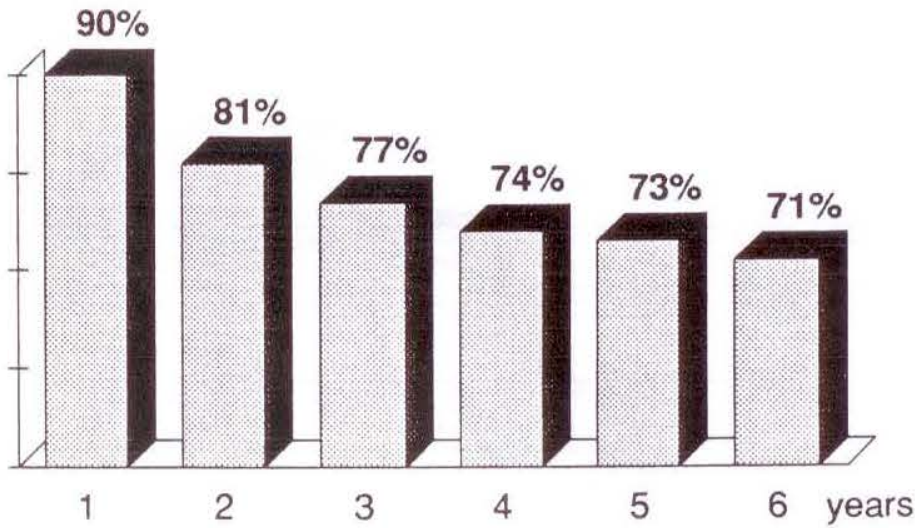

Figure 3) Frequency of recurrences after initial success in 318 patients with initial success. The frequency of recurrences was calculated by life table analysis during the first six-year follow-up period. The numbers indicate the percentage of patients free from recurrence

ces was calculated by life table analysis. The comparison of frequencies were tested by the $\chi 2$ test (or Fisher's exact probability test when the samples were small in size). The other comparisons were tested by analysis of variance followed, if necessary, by the criterion of the least significant difference.

Cost estimates: Even if endoscopic laser treatment should not be considered as an alternative therapy to surgical resection, a comparison of the average charges for lesions of identical size treated by both techniques could be useful. The direct charges, including hospital costs, doctor's fees and ambulance transportation for a patient living in Lille area and treated in the authors' hospital, were estimated as a function of the circumferential extension of the tumour base. As a comparison to the United States, these costs were also estimated for a patient living in Los Angeles and treated at UCLA Center for the Health Sciences (personnal communications).

\section{RESULTS}

Treatment was not completed in 44 patients because 20 were lost to followup, 15 died from another condition during treatment and nine are still under treatment. Results for the 343 remaining patients are presented in Figure 2. Immediate results: Three hundred and eighteen patients were successfully treated after an average of 5.7 treatments during an average period of 3.7 months (range 0.2 to 21 months). This represents $92.8 \%$ of the patients whose treatment was completed.

An invasive carcinoma was detected in 22 patients $(6.4 \%)$ on biopsy specimens obtained during laser treatment. The average delay between the beginning of the treatment and the diagnosis of cancer was 5.7 months (range 1 to 16 months). Twelve patients had surgery (three segmental resections and nine abdominoperineal resections). Histologic examination of the surgical specimen revealed only high grade dysplasia in four patients. Therefore, a true carcinoma developed only in 18 patients $(5.2 \%)$. Following the Aslier-Collers' classification (7), the extension of the cancer in the eight operated patients was A in two, B2 in two, $\mathrm{Cl}$ in three and $\mathrm{C} 2$ in one. Ten patients with positive biopsies could not tolerate surgery. Nine continued to be treated by laser for palliation of symptoms. However, complete destruction of the tumour with negative biopsies was obtained in four patients without local recurrence or metatasis during a 35-month average follow-up range ( 12 to 60 months). Among the five others, one died from a bronchogenic cancer, two died from rectal cancer six and 15 months later, and the last two patients are still being followed for 


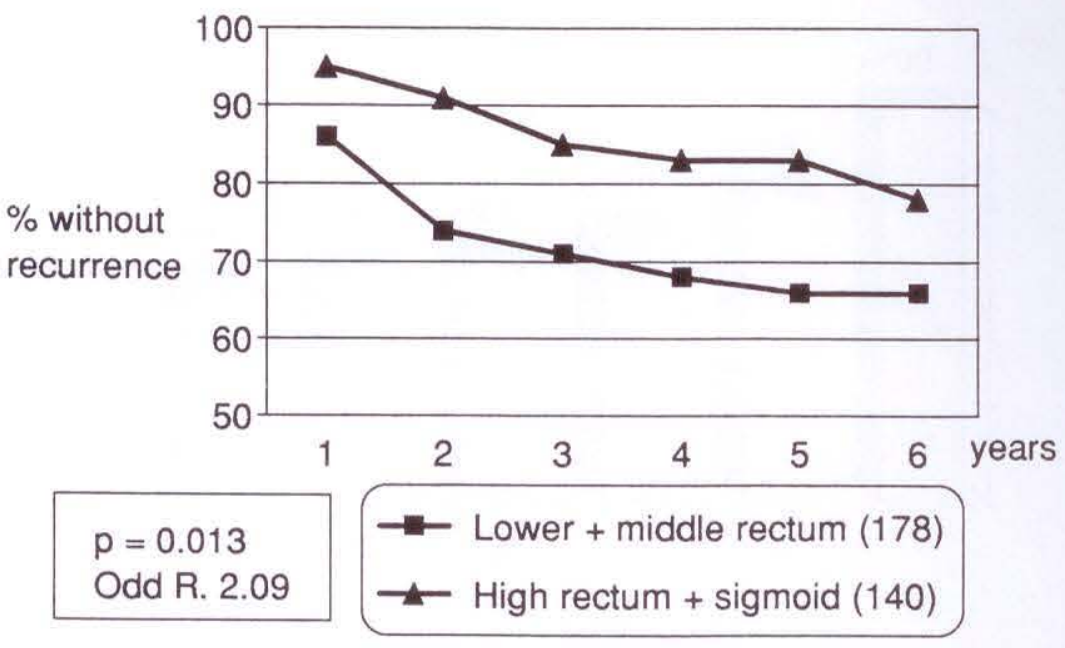

Figure 4) Effect of the reason for treatment on the frequency of recurrences after initial succcess. The frequency of recurrences was calculated by life table analysis during the first six-year follow-up period

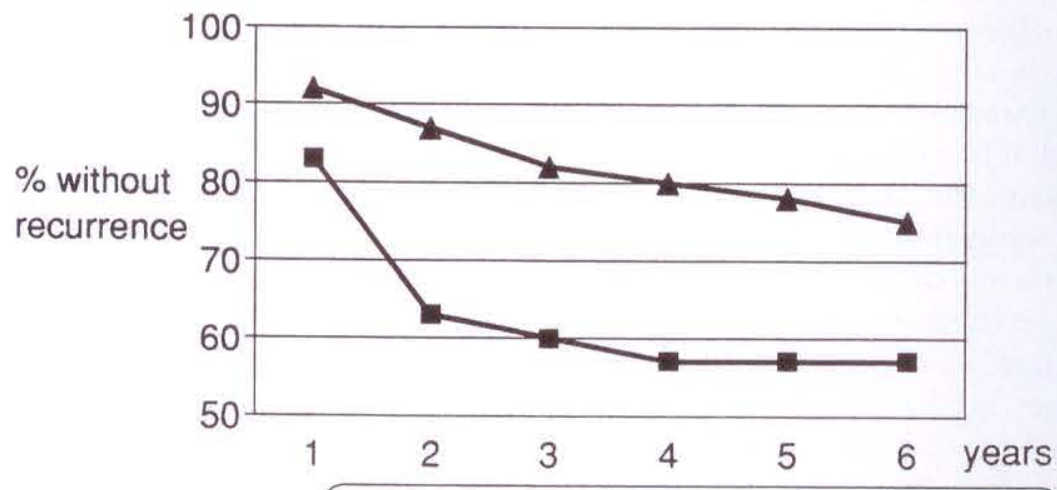

$\mathrm{p}<0.001$

Odd R. 2.4

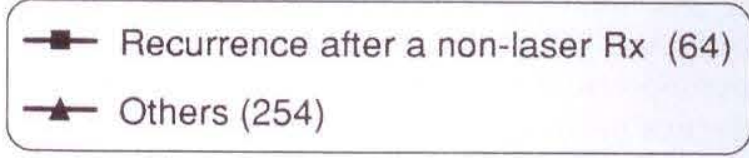

Figure 5) Effect of the location on the frequency of recurrences after initial success. The frequency of recurrences was calculated by life table analysis during the first six-year follow-up period

TABLE 1

Effect of the circumferential extension of the tumour base on the number of laser applications and duration of initial treatment

\begin{tabular}{lccl}
$\begin{array}{l}\text { Circumferential } \\
\text { extension }\end{array}$ & $\begin{array}{c}\text { Number of } \\
\text { patients }\end{array}$ & $\begin{array}{c}\text { Number of laser } \\
\text { applications }\end{array}$ & Duration \\
\hline C1 & 153 & 3.0 & 2.3 months \\
C2 & 135 & 7.1 & 4.4 months \\
C3 & 30 & 13.1 & 7.8 months \\
Total & 318 & 5.7 & 3.7 months \\
\hline
\end{tabular}

The three groups are different for the number of laser applications and the duration of treatment $(P<0.0001)$ palliation for four and 15 months. The last patient was successfully treated by local radiation.

Three patients $(1 \%)$ could not be successfully treated. All had a C3 lesion previously treated by a nonlaser procedure. Two patients were treated previously with electrocoagulation which resulted in a very tight stenosis making endoscopic treatment impossible. Therefore only diverting colostomy could be performed. The third patient had been treated by surgical transanal resection. He developed a stenosis after $\mathrm{Nd}$ :YAG laser treatment. The stenosis was not tight enough to require a colos. tomy but made the endoscopic treatment possible.

Long term results: The average followup of the 318 initially successfully treated patients was 30.6 months. Among them, 221 are still being followed for an average of 35 months (range 1 to 110 ). Fifty-nine were lost to follow-up after an average period of 19 months (range 1 to 98), and 38 died from another condition after a follow-up of 24 months (range 1.7 to 63). Among these 318 patients, 51 had a recurrence $(16 \%)$. Most of the recurrences were detected during the the first two years (Figure 3 ) and the average delay between the end of the initial treatment and detection of a recurrence was 18.6 months. Nine patients had two recurrences and two patients had three recurrences. All recurrences were easily retreated in 46 patients with an average of 2.2 treatments. Three patients with a recurrence are still being treated.

In the last two patients, a cancer was detected by biopsy. The first patient was referred for laser treatment because of a recurrence six months after transanal resection. No malignancy was found on the resection specimen nor on the biopsies performed on the first recurrence. A second recurrence of villous adenoma occurred 16 months after laser treatment and was found to be malignant. The second patient had a recurrence with positive biopsies one year after initial laser treatment. Both patients were treated by abdominoperi. neal resection. Following the AstlerColler's classification (7), the extension of the cancer was $\mathrm{Cl}$ in the first 
patient and $\mathrm{B} 1$ in the second patient. These two patients were both doing well at 14 and 22 months follow-up.

Tolerance and complications: The treatment was generally well-accepted by the patients and only $5.1 \%$ were lost to follow-up during initial treatment. During treatment with the $\mathrm{Nd}: Y \mathrm{AG}$ laser some patients experienced warmth in the rectum when the tumour was close to the anus; argon or 0.532 $\mathrm{Nd}$ :YAG lasers were used instead and were well-tolerated. For two or three days after a laser session, patients often had spotting with blood and evacuation of necrotic tissue. Three patients experienced fever $\left(38^{\circ} \mathrm{C}\right)$ for two days unassociated with pain and this spontaneously abated. Symptomatic stenosis developed in eight patients without further consequence. No fistulae were observed. Nine complications $(2.3 \%)$ occurred. One patient experienced a hemorrhage requiring transfusion. The hemorrhage was related to a traumatic ulceration of the laser treated area caused by a thermometer. Symptomatic stenosis developed in seven patients and required endoscopic dilations. A perforation occurred in the sigmoid 12 $\mathrm{h}$ after vaporization of a $\mathrm{Cl}$ tumour with the $0.532 \mathrm{Nd}: Y A G$ and required surgical treatment. Since this accident, the power used with the $0.532 \mathrm{Nd}$ :YAG has been reduced from $15 \mathrm{~W}\left(6000 \mathrm{~W} / \mathrm{cm}^{2}\right)$ to $10 \mathrm{~W}\left(4000 \mathrm{~W} / \mathrm{cm}^{2}\right)$.

Factors affecting the results: The circumferential extension of the tumour base was the only factor affecting duration of the initial treatment (Table 1), the rate of undetected cancers before treatment and the occurrence of stenosis requiring dilation.

The rate of undetected cancers was $3 \%$ in $\mathrm{Cl}$ and $\mathrm{C} 2$ tumours, versus $20 \%$ in $\mathrm{C} 3$ tumours $(\mathrm{P}<0.001)$. Stenosis requiring dilation was observed in $20 \%$ of the $\mathrm{C} 3$ tumours and $0.3 \%$ in $\mathrm{Cl}$ and $\mathrm{C} 2$ tumours $(\mathrm{P}<0.001)$.

The recurrence rate after initial treatment, calculated by life table analysis (Figures 4 to 7 ), was affected by the initial histology, the reason for treatment and the location, but not by the circumferential extension of the tumour base.

Treatment cost: In a previous series

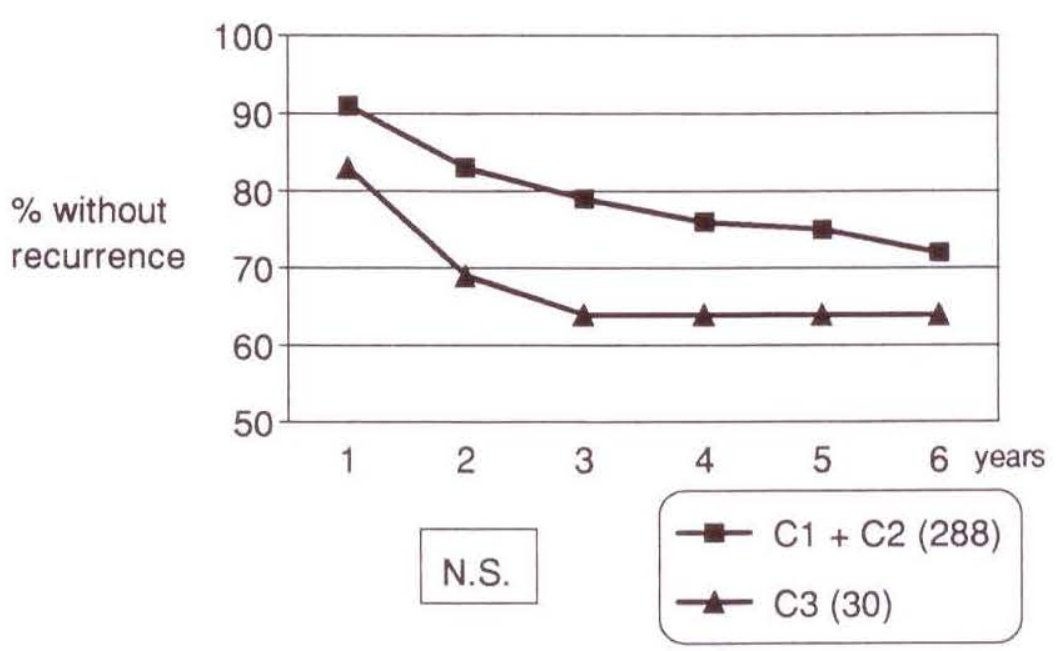

Figure 6) Effect of circumferential extension on frequency of recurrences after initial success. The frequency of recurrences was calculated by life table analysis during the first six-year follow-up period

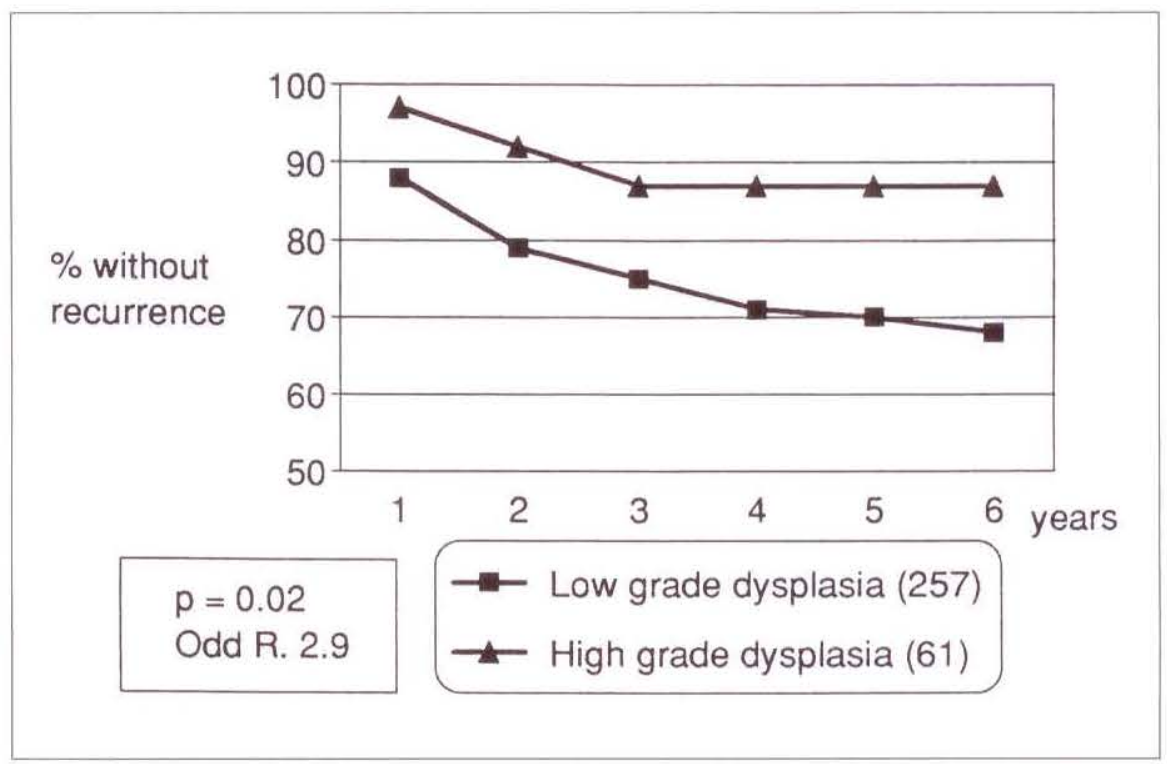

Figure 7) Effect of histology on frequency of recurrences after initial success. The frequency of recurrences was calculated by life table analysis during the first six-year follow-up period

involving 208 patients (8), the direct charges - including hospital costs, doctor's fees and ambulance transportation for a patient living in Lille area and treated in hospital - for $\mathrm{Cl}, \mathrm{C} 2$, and $\mathrm{C} 3$ tumours were estimated. The laser costs included, respectively, 3.2, 7.8 and 13.5 laser treatments, two, three, and four control endoscopies without treatment and the corresponding ambulance transportation. The surgical costs included the costs of surgery and 6,10 , and 14 days, respectively, of hospitaliza- tion. This resulted in laser charges being, respectively, 28,37 and $40 \%$ of the surgery charges in Lille. For Los Angeles, the estimated direct costs of care for laser were 31,52 , and $69 \%$ of surgery for $\mathrm{Cl}, \mathrm{C} 2$, and $\mathrm{C} 3$ tumours, respectively.

\section{DISCUSSION}

Two questions have to be answered about endoscopic laser treatment for villous adenomas: Is it a safe and efficient technique?; and which patients 
should be referred for endoscopic laser treatment? The first question can be answered by considering the rates of initial success, complications and cancer during the initial treatment and the rate of recurrence during the follow-up period. The second question can be addressed by comparing the results and cost of endoscopic laser with surgery.

Four series using endoscopic laser treatment for villous adenoma, involving a total of 269 patients (9-12), have been reported since the authors' initial results were published in 1985 (3). Slight differences in the technique and patient selection exist in regard to the present authors' own series. The $\mathrm{Nd}$ :YAG laser was used alone, without adjuvant argon laser, in all the other series. The tumours were present in the rectum only (9) or rectum and colon $(9,11,12)$. The pretreatment history was benign villous tumours only $(10$, 12), benign villous and tubular adenomas, or included focal carcinomas (11).

The initial success rate achieved in the present series $(92.8 \%)$ compares favorably with those reported in other sesries of $88 \%(10), 89 \%(11)$ and $79 \%$ $(9,12)$. Complications such as hemorrhage, stenosis, perforations or fistulae were rarely reported. The complication rate in the present series was $2.3 \% \mathrm{com}$ pared with $6 \%(12), 12.5 \%$ (9), $14 \%$ (11) and $15 \%$ (10). In the last series, six of eight complications were indicated as stenosis, but it was not stated whether they were symptomatic. This may account for the difference from other series where only symptomatic stenosis were reported. The authors' lower complication rate can also be explained by the location of the treated tumours. Three series include villous adenomas above the rectosigmoid $(9,11,12)$ and have a higher complication rate than the present series where the indications were limited to the rectum and sigmoid. Because of the thickness of the bowel wall, the danger of perforation and delayed thermal stenosis is higher above the rectosigmoid. In the authors' opinion, the risk:benefit ratio is acceptable for locations in the rectum and the sigmoid colon and not acceptable for locations above the sigmoid colon.
The recurrence rate was given in percentage of recurrences detected during the average follow-up period ( $16 \%$ during a 30-month average follow-up in the present series) or calculated by life table analysis (10\% at one year, $19 \%$ at two years and $29 \%$ at six years in the present series). In the other series, it was $3.8 \%$ during a 8.4 month follow-up (10), $25 \%$ for 18 months (12), 37.5\% for 16.5 months (9), and, respectively, 27 and $46 \%$ at one and two years (11). Most recurrences were successfully retreated except in one series (9) where $66 \%$ of the recurrences failed retreatment.

The major problem with laser management of villous adenomas is that no specimen is available for complete histologic study (3) and, consequently, a tumour with an undetected invasive cancer could be inappropriately treated. The malignant potential of villous adenomas is well-known, with a rate of invasive carcinoma estimated from 9 to $28 \%(13,14)$. These data were obtained from surgical series without referring to the pretreatment assessment. Clinical assessment (without biopsy) was found to be $91 \%$ accurate in a series of 151 patients (15), and the biopsy assessment was $97 \%$ accurate in a series of 128 patients (13). Therefore, the risk of missing an invasive carcinoma with pretreatment biopsy should not be overestimated. In the laser series, the rates of undetected cancers were either lower than the $5.2 \%$ of the present series $(0 \%$ $[10,12], 2.5 \%[11])$ or higher (15\% [9]). Among the 18 patients in the present series with an undetected cancer, 10 were nonsurgical candidates and treatment was inappropriate in eight, delaying surgery for a few months.

Regarding the results of these five series, the endoscopic laser treatment appears to be efficient and safe. The results of the authors' series are slightly better than those of the four others; the success rate is the highest and the complication and recurrence rates (for an identical average follow-up period) are the lowest. This could be explained by the fact that the cases were limited to the rectosigmoid and by the particularities of the treatment technique. Bulky areas of the tumours were coagu- lated with the Nd:YAG laser while the smaller areas were vaporized with the argon laser. The use of the argon laser is not widespread in gastroenterology, but those who have access to such a laser (16) prefer the absence of delayed effects, and the reduced risk of perforation and thermal stenosis compared with $\mathrm{Nd}$ :YAG laser.

Transanal, transsacral or transabdominal resections have the major advantage of allowing a total histologic examination of the tumour. But complications and recurrences are also reported after surgery. The complication rate was $21 \%$ in two large series (17, 18 ), including a $2.5 \%$ death rate. The recurrence rates after surgery range from 3.6 to $42 \%(13,17-19)$, the highest rates occurring after transanal surgery.

The cost of any new treatment is a major problem, but little data are available (20). Each country has different cost accounting and health insurance systems, making comparisons of absolute costs difficult. Therefore, the relative cost of laser treatment and surgery was assessed (estimating only the direct costs: hospital, doctor and ambulance transportation fees). This estimation is favorable of laser treatment for all three types of tumours ( $\mathrm{Cl}$ to $\mathrm{C} 3$ ). If indirect costs were included (loss of time from work, disability, complications, etc), laser treatment would probably look more favourable, especially for $\mathrm{Cl}$ tumours which require only a few laser treatments.

Surgery is more expensive, has more complications (some being fatal) and has more recurrences (at least for transanal surgery) than endoscopic laser. On the other hand, endoscopic laser requires multiple treatments for complete destruction of the tumour and carries the risk of mistreating an undetected carcinoma. However, these two techniques should not be regarded as competitive but rather as complementary. Endoscopic laser treatment should be used only after a discussion among the endoscopist, surgeon and anesthetist $(3,8)$. Their consensus should then be discussed with the patient and family members.

This study has identified certain factors which affect the results and clarify the indications for endoscopic laser 
treatment for rectosigmoid villous adenoma. Patients with a C3 tumour should be referred for laser only if they are not candidates for surgery. This is because the laser treatment takes too long, and the risks of undetected cancer and stenosis induced by the treatment are too high. For patients with $\mathrm{Cl}$ and C2 tumours, the risk of fatal complica-

\section{REFERENCES}

1. Fleischer D. Lasers and colon polyps. The courtship continues. Gastroenterology 1986;90:2024-5.

2. Jensen DM. Lasers in the gastrointestsinal cancer war and on other fronts. Gastroenterology 1984;87:974-6.

3. Brunetaud JM, Mosquet L, Houcke M, et al. Villous adenomas of the rectum. Results of endoscopic treatment with argon and Nd:YAG lasers.

Gastroenterology 1985;89:832-7.

4. Riddel RH, Goldman H, Ransohoss DF, et al. Dysplasia in inflammatory bowel disease: Standardized classification with provisional clinical applications. Hum Pathol 1983;14:931-68.

5. Reid BJ, Haggitt RC, Rubin CE, et al. Observer variation in the diagnosed dysplasia in Barrett's esophagus. Hum Pathol 1988;19:166-78.

6. Brunetaud JM, Maunoury V, Ducrotte $\mathrm{PH}$, et al. Palliative treatment of rectosigmoid carcinoma by laser endoscopic photoablation. Gastroenterology 1987;92:663-8,

7. Astier VB, Coller FA. The prognostic significance of direct extension of carcinoma of the colon and rectum. tions after surgery has to be balanced against the risk of delaying detection of a carcinoma with laser. The treatment proposed to the patient has to be discussed case by case. The ambulatory but repeated endoscopic laser treatment will be safer for an elderly and fragile patient whereas a younger and healthier patient may prefer to be treat-

Ann Surg 1954:139:846-52.

8. Brunetaud JM, Maunoury V, Ducrote P, Cochelard D, Cortot A, Paris JC. Palliative treatment of rectosigmoid carcinoma by endoscopic laser photoablation. Gastroenterology. 1987;92:663-8.

9. Mathus-Vliegen EMH, Tytgat GNJ. $\mathrm{Nd}$ Y $\mathrm{AG}$ laser photocoagulation in colorectal adenoma. Evaluation of its safety, usefulness and efficacy. Gastroenterology 1986;90:1865-73.

10. Escourrou J, Delvaux M, De Bellisen F, Frexinos J, Ribet A. Traitement par laser Nd:YAG des tumeurs villeuses redales: Expérience de 57 cas. Gastroenterol Clin Biol 1987;11:276. (Abst)

11. Souquet JC, Sabben G, Chavaillon A, et al. Traitement laser des tumeurs villeuses rectales. Ann Gastroenterol Hepatol 1987;23:311-4.

12. Naveau S, Zourabichvili O, Brunie F, Poitrine A, Perrier C, Chaput JC. Traitement par le laser Nd:YAG des tumeurs villeuses colo-recrales. Gastroenterol Clin Biol 1988;12:604-9.

13. Chiu YS, Spencer RJ. Villous lesions of the colon. Dis Colon Rectum 1978;21:493-5.

14. Quan SN, Castro EB. Papillary ed surgically in a single procedure. The inaccessibility of villous adenoma to transanal surgery favours laser therapy because of the higher rate of complications for transsacral or transabdominal surgery. The risk of complications and the disturbance caused by a total colon preparation preclude laser treatment for lesions above the rectosigmoid.

adenomas (villous tumors). A review of 215 cases. Dis Colon Rectum $1971 ; 14: 267-80$

15. Nivatvongs S, Nicholson JD, Rothemberger DA, et al. Villous adenomas of the rectum, the accuracy of clinical assessment. Surgery 1980;87:549-51.

16. Dixon JA, Burt RW, Roetering RH, McCloskey DW. Endoscopic argon laser photocoagulation of sessile polyps. Gastrointest Endosc 1982;28:162-5.

17. Thompson JP. Treatment of sessile and tubulovillous adenomas of the rectum: Experience of St Mark's Hospital. Dis Colon Rectum 1977;20:467-72.

18. Malafosse M, Roge P. Surgical management of villous tumors of the colon and rectum. Dig Surg 1984:1:168-71.

19. Delile P, Marche C, Edelman G. Les tumeurs villeuses du colon et du rectum. Problèmes diagnostiques et thérapeutiques. Ann Chir 1977;31:829.42

20. Jensen DM. Economic assessment of peptic ulcers disease treatments. Scand J Gastroenterol 1988;23(Suppl 146):214-23. 


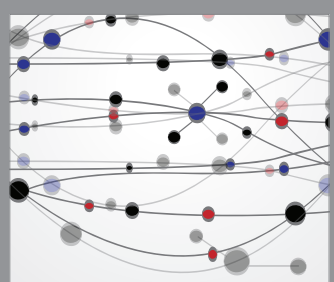

The Scientific World Journal
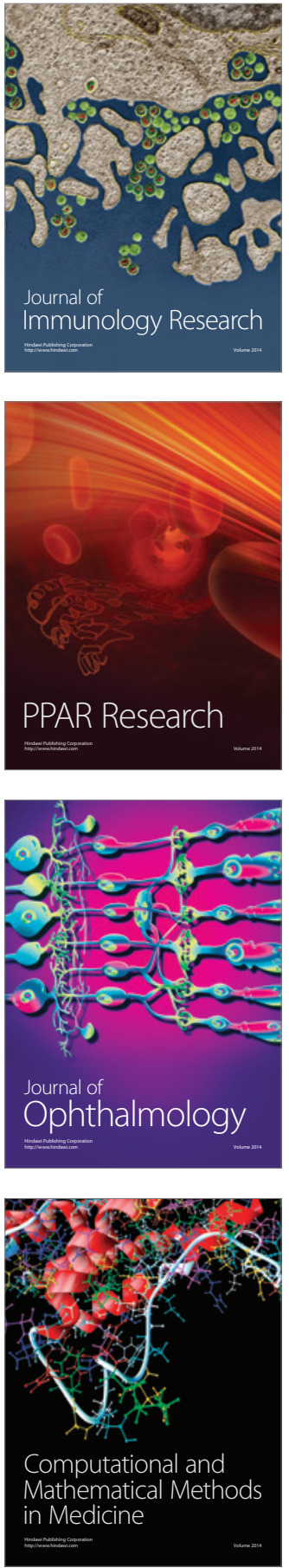

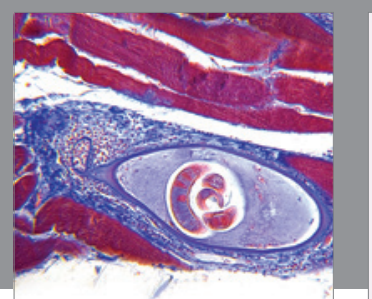

Gastroenterology Research and Practice

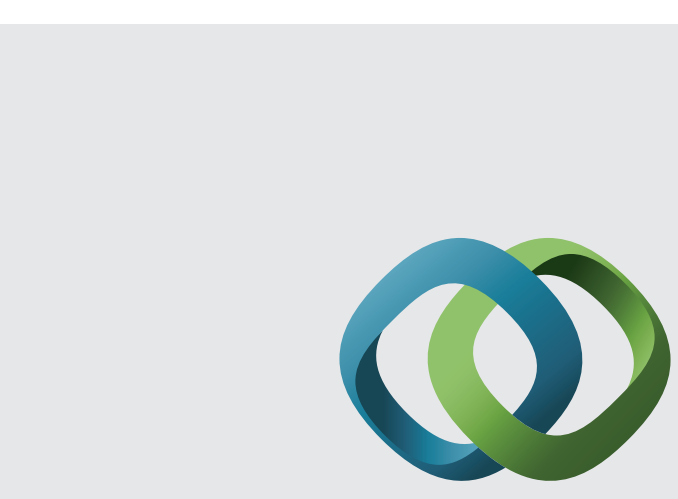

\section{Hindawi}

Submit your manuscripts at

http://www.hindawi.com
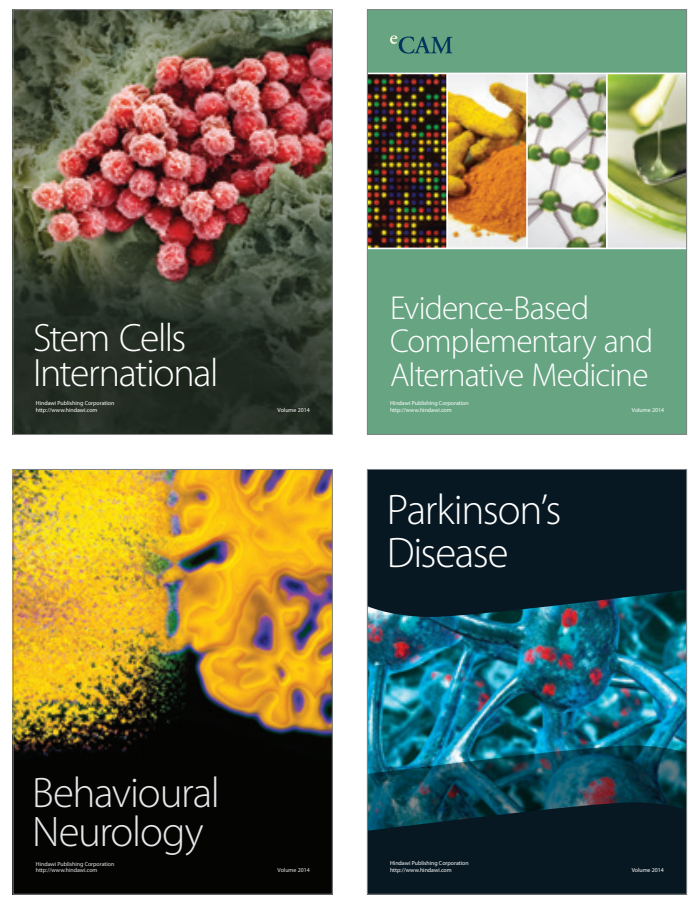
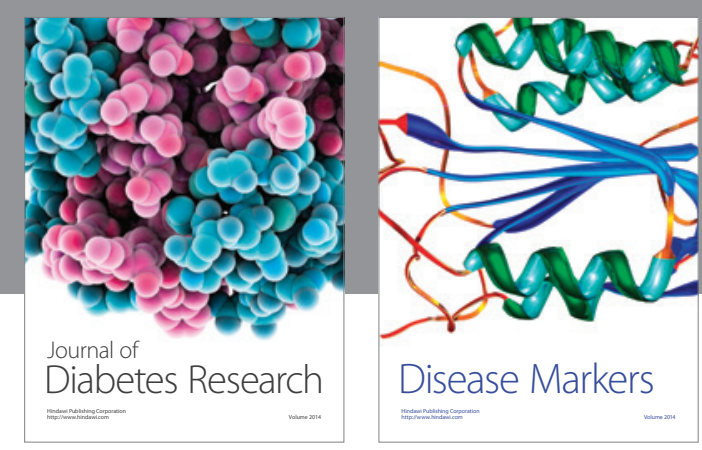

Disease Markers
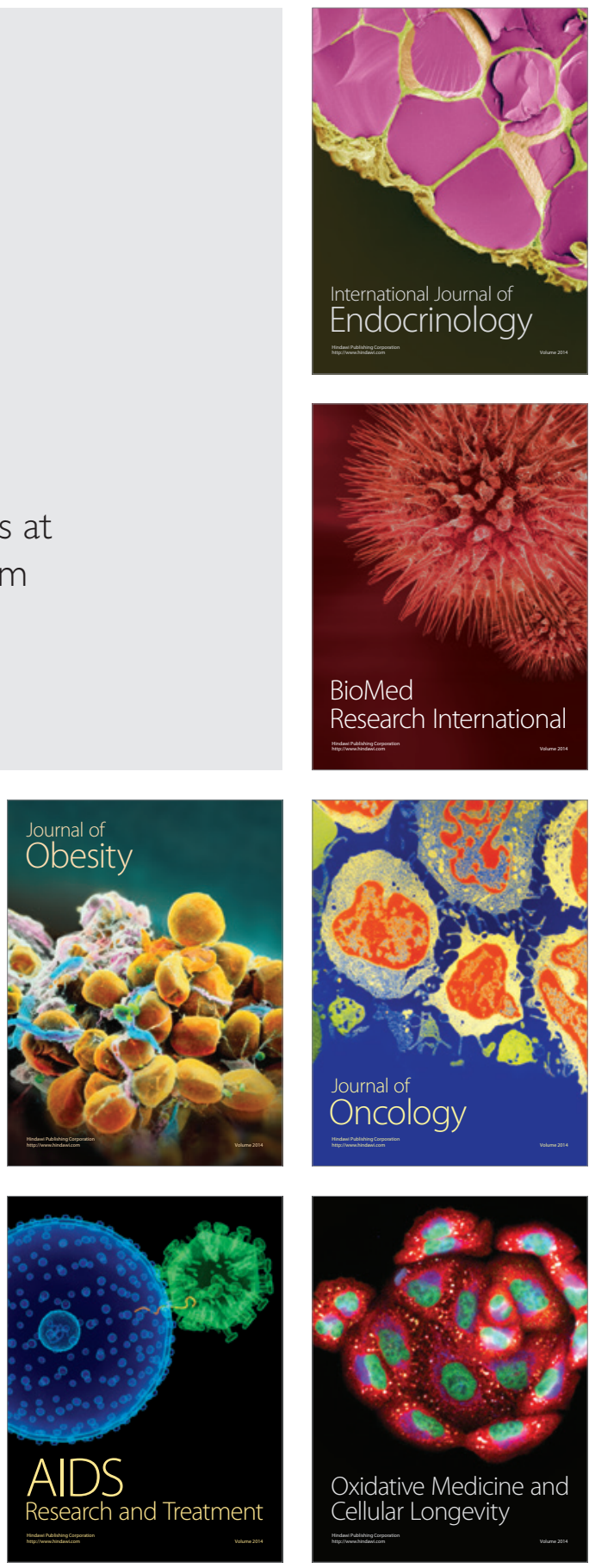